\section{Total aortic occlusion associated with SARS-CoV-2 (COVID-19) infection: Video Image}

\author{
Yasin Kilic, Hakan Usta, Izatullah Jalalzai, Ferhat Borulu and \\ Bilgehan Erkut*
}

Department of Cardiovascular Surgery, Medical Faculty, Atatürk University, Erzurum, Turkey

\section{Abstract}

Acute pulmonary damage and vascular coagulopathy appear to be frequent in patients with SARS-CoV-2 infection relation to corona-virus. The inflammatory process accompanying the infection and excessive coagulation state is one of the most important causes of patient loss.
More Information

*Address for Correspondence: Bilgehan Erkut, Professor, MD, Department of Cardiovascular Surgery, Medical Faculty, Atatürk University, Erzurum, Turkey, Tel: 0090533 7451006; 00904423448899 ;

Email: bilgehanerkut@yahoo.com

Submitted: April 09, 2021

Approved: April 15, 2021

Published: April 16, 2021

How to cite this article: Kilic $Y$, Usta $\mathrm{H}$, Jalalzai I, Borulu F, Erkut B. Total aortic occlusion associated with SARS-CoV-2 (COVID-19) infection: Video Image. J Clin Med Exp Images. 2021; 5: 004-004

DOI: 10.29328/journal.jcmei.1001020

Copyright: @ 2021 Kilic Y, et al. This is an open access article distributed under the Creative Commons Attribution License, which permits unrestricted use, distribution, and reproduction in any medium, provided the original work is properly cited.

(D) Check for updates

OPEN ACCESS
A 62-year-old male patient, who did not have any previous cardiac or lung problems, was admitted to our hospital with coldness, chills and cyanotic discoloration in the lower extremities, as well as back pain and shortness of breath. The computed tomography angiography revealed an acute thrombotic occlusion of the thoracal-abdominal and infra-renal aorta extending into the common iliac arteries (Video). Under local anesthesia, aorto-femoral embolectomy was performed via bilateral femoral arteries. Abundant thrombus material was removed from the aorta, iliac and femoral arteries (Figure 1).

\section{Discussion}

Although infiltrations related to lung involvement are more common in patients with COVID-19, thrombotic complications can also be seen [1]. Hypercoagulability and thrombotic disease in patients with COVID-19 is a rare

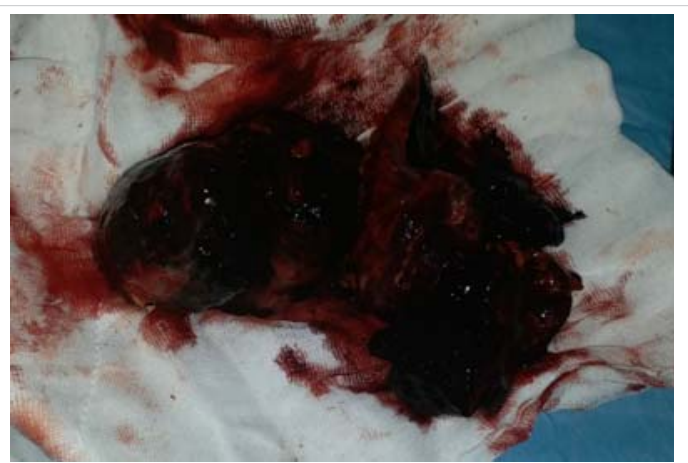

Figure 1: Dense thrombus material removed by femoral embolectomy.

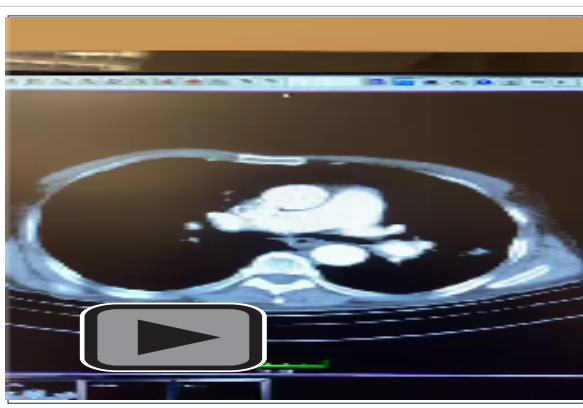

Video: Computed tomography showing total aortic occlusion starting from the thoracic aortic level to the iliac arteries.

condition that can be seen even if the PCR test is negative. It may cause cerebral, cardiac or peripheral vascular occlusions as in our patient, regardless of the age of the patients, their atherosclerotic tendency or additional disease [2]. For this reason, every patient should be closely monitored for a disastrous and distressing clinical picture, and anticoagulant therapy should be continued for a certain period of time.

\section{References}

1. Zhang $Y$, Xiao M, Zhang S, Xia P, Cao W, et al. Coagulopathy and antiphospholipid antibodies in patients with Covid-19. N Engl J Med. 2020; 382: e38.

PubMed: https://pubmed.ncbi.nlm.nih.gov/32268022/

2. Vacirca A, Vacirca A, Faggioli G, Pini R, Teutonico P, Pilato A, Gargiulo M. Unheralded Lower limb threatening ischemia in a COVID-19 patient. Int J Infect Dis. 2020; 96: 590-592.

PubMed: https://pubmed.ncbi.nlm.nih.gov/32447121/ 